\title{
Sociedade e natureza nos trabalhos acadêmicos de Pós-graduação em Geografia e Geociências da UFSM
}

\author{
Renata Huber ${ }^{1}$, Bernardo Sayão Penna e Souza² \\ ${ }^{1}$ Estudante de Pós-graduação em Geografia na UFRGS; área de Análise Ambiental; e estudante de Graduação em Geografia \\ Licenciatura na UFSM.E-mail: huber.renata@gmail.com \\ ${ }^{2}$ Universidade Federal de Santa Maria/ Professor do Departamento de Geografia e Geociências. E-mail: bernardosps@yahoo.com
}

Recebido em 01/2012. Aceito para publicação em 04/2012.

Versão online publicada em 17/11/2012 (http://seer.ufrgs.br/paraonde)

\begin{abstract}
Resumo - A relação sociedade/natureza é marcada pela separação das Ciências Naturais e Humanas, herança da cultura e Ciência ocidentais. Atribui-se a essa distância entre a Sociedade e a Natureza, o mito da expulsão do Paraíso, a separação na filosofia pré-socrática do espírito/matéria e mais uma série de acontecimentos da historia do Ocidente. Essa herança foi deixada a todas as Ciências, inclusive à Geografia, a qual se torna, em sua evolução, a Ciência de contato Sociedade/Natureza. Nesta pesquisa objetivouse desvelar como a conhecida dicotomia Sociedade/Natureza é abordada nos trabalhos de Pós-graduação em Geografia e Geociências da UFSM. Foram examinados 26 trabalhos de Pós-graduação (entre monografias e dissertações) que versam sobre análise ambiental. Destes, observaram-se o conteúdo e o discurso defendidos na fundamentação teórico/metodológica comparando-os com a análise dos resultados feita por seus autores. Constatou-se que a desvinculação entre a Sociedade e a Natureza persiste na interpretação da maioria dos autores. Em geral, a fundamentação teórica e de método buscam aplicar a visão sistêmica do objeto de estudo, no entanto, estes autores demonstram na análise de seus resultados que o entendimento do objeto de estudo é fragmentado, principalmente em relação à sociedade e à natureza. Verificou-se em menor ocorrência trabalhos que discutem sociedade/natureza sem dicotomizá-las. Coincidentemente, estes iniciam suas pesquisas caracterizando os aspectos e processos sociais.
\end{abstract}

Palavras-chave: Sociedade/Natureza. Evolução Da Ciência Geográfica. Pós-graduação. Metodologia Científica. Mitos Em Geografia.

\section{Introdução}

A relação sociedade/natureza ou homem/meio tornou-se, no decorrer do desenvolvimento da Ciência geográfica a principal temática e preocupação dos geógrafos. Sendo o objeto de estudo da Geografia, existe o comprometimento de entender essa relação de maneira integrada, sistêmica.

Por outro lado, a interpretação da relação sociedade/natureza é resultado da formação histórica e cultural predominantemente ocidental, ou seja, possui relação direta com a construção da Ciência ocidental. Por conseguinte, a Ciência geográfica traz em sua estrutura conceitual, filosófica e metodológica os mesmos valores constituintes da Ciência formal ocidental e transmite essa herança a todos aqueles que venham a ser seus pesquisadores.

Com a finalidade de caracterizar a visão dos estudantes vinculados ao Programa de Pósgraduação em Geografia e Geociências da Universidade Federal de Santa Maria (PPGGeo/UFSM) acerca da relação sociedade/natureza buscou-se, como fonte de informação, os trabalhos defendidos no referido programa de $\mathrm{PG}$, no período compreendido entre os anos de 1991 a 2010.

Por conseguinte, foram pesquisadas, através do sistema de catálogo on-line da Biblioteca Central da UFSM, as monografias e as dissertações defendidas no PPGGeo, que envolvem em sua pesquisa o estudo da relação sociedade/natureza. Destas, foi possível examinar, a partir dos discursos da fundamentação teórico-metodológica e da análise dos resultados/considerações finais dos trabalhos, as interpretações recorrentes de como se abordam essas relações.

\section{Sociedade e natureza na formação da ciência ocidental}

Muitas leituras induzem a favor de que existe, em teoria, uma desvinculação entre homem e natureza no Ocidente. Gonçalves (1989) associa essa desvinculação a vários fatores da história do 
Ocidente, e Diegues (1996) a atribui ao mito do Paraíso perdido.

Para Gonçalves (1989) esta desvinculação no Ocidente acontece a partir do momento em que physis (conceito que surge na filosofia grega présocrática, também chamado de período Cosmológico), que significava espírito, pensamento, inteligência, logos, ganha um novo conceito entre os filósofos gregos. Physis, que antes a toda matéria impregnava, a partir de Aristóteles, vai pouco a pouco desumanizando a natureza, apartando-se dela, separando matéria e espírito. Outro fator que segundo o autor causou maior impacto na oposição homem x natureza e espírito x matéria, foi a influência judaico-cristã. No cristianismo ocidental Deus sobe aos céus e de fora age sobre a vida; na Idade Média isso separará espírito e matéria (GONÇALVES, 1989). E acrescenta que foi na Idade Média que teve início a prática de dissecar cadáveres no ocidente europeu, e assim foi em decorrência lógica do pensamento filosófico que separa o corpo do espírito; se o que anima o corpo não está mais presente, ele pode ser dissecado, dividido, torna-se por fim, um objeto.

Com Descartes completa-se a separação homem/natureza, espírito/matéria, sujeito/objeto, a qual se tornará o centro do pensamento moderno (GONÇALVES, 1989). A adição do antropocentrismo ao mercantilismo e colonialismo, consagram, segundo Gonçalves (1989), a capacidade humana de dominar a natureza, afinal, a natureza já não possui alma. 0 mesmo autor ainda escreve que com o Iluminismo a metafísica é abandonada, seguindo o preceito de que para se compreender o mundo necessita-se partir daquilo que é tangível, do físico; o Capitalismo e a Revolução Industrial, talvez sejam a base dessas idéias.

No século XIX, ciência e técnica são o centro da vida humana,

a natureza, cada vez mais é um objeto a ser possuído e dominado, é agora subdividida em física, química, biologia. [E] o homem, [dividido] em economia, sociologia, antropologia, história, psicologia, etc. Qualquer tentativa de pensar o homem e a natureza de uma forma orgânica e integrada torna-se agora mais difícil [...] (GONÇALVES, 1989, p. 34).

Logo, aquele que não pensa de modo dividido e dicotomizado é caracterizado como alguém que perdeu sentido da realidade; que quer voltar ao passado é tido como sonhador, irracional, diz Gonçalves (1989).
As ciências da natureza se separam das ciências do homem; cria-se um abismo colossal entre uma e outra [e] tudo isso não é só uma concepção de mundo. A ecologia enquanto saber e, sobretudo, 0 movimento ecológico tentam denunciar as conseqüências dessas concepções, embora o façam, muitas vezes, permeados pelos princípios e valores dos seus detratores [...] (GONÇALVES,1989, p.35).

Diegues (1996) corrobora com a idéia de Gonçalves a respeito de os movimentos ecológicos estarem "contaminados" com os princípios e valores de seus detratores, pois afirma que a dicotomia homem/natureza é devido à expulsão do homem do Paraíso; ou seja, esse arquétipo, essa imagem mítica que se tem das áreas preservadas (por exemplo) não conterem a presença humana é um grande obstáculo para a efetiva conservação ambiental. 0 homem é visto como prejudicial à natureza. Esse mito, o do Paraíso perdido, reproduzido nas áreas de preservação, vem a reforçar o afastamento entre homem e natureza (DIEGUES, 1996).

Os parques nacionais inauguraram as áreas de conservação e tiveram sua origem devido às analogias com o Paraíso perdido, onde o homem houvera sido expulso, por isso a ausência deste é prevista, a principio, nas Unidades de Conservação (UCs). "A concepção cristã de paraíso, existente no final da Idade Média e no período anterior ao descobrimento da América, era de uma região natural, de grande beleza e rigorosamente desabitada, de onde o homem tinha sido expulso após o pecado original" (DIEGUES, 1996, p. 27). Dessa maneira, valoriza-se toda a natureza, menos a humana (DOWIE, 2008). "Separar o homem da natureza é, portanto, uma forma de subordiná-lo ao capital" (GONÇALVES, 1989, p.116).

\section{Sociedade e natureza na herança da Ciência geográfica}

A herança da Geografia representa os caminhos que todo o pesquisador em Geografia percorre e conhece antes de realizar suas próprias pesquisas. Em cada espaço e em cada tempo tem-se um conjunto de teorias que formam o corpo teórico de uma Ciência, sendo assim, cada pesquisador é contemporâneo do seu próprio "tempo" de formação acadêmica, ou seja, cada pesquisador é contemporâneo de sua época e está em consonância, na maioria dos casos, com as teorias legitimadas e aceitas pela Ciência.

Ainda que algumas teorias e alguns métodos tenham sido falseados, o pesquisador tem a liberdade de escolher o que melhor lhe serve para 
realizar a pesquisa. No entanto, ainda assim, terá de passar, necessariamente, por aquilo que já foi feito em Geografia. Seus autores consagrados, seus trabalhos, seus suportes teóricos, seus métodos, suas ideologias. São caminhos que já foram traçados e que receberam um tratamento científico antes de serem escritos e transmitidos às gerações vindouras de cientistas e pesquisadores, de alunos e professores. São os caminhos herdados por todo aquele que pesquisa em Ciência Geográfica, e aqui seu intuito é desenhar que caminhos são esses e que mitologias trazem consigo, especialmente no que se refere à relação homem/meio, sociedade/natureza. Logo, como foi o desenvolvimento da Geografia até o momento presente?

Para entender a Geografia da Idade Média é preciso ter ciência de que esta era muito influenciada pela Igreja, era uma extensão da Bíblia; no Renascimento, era uma forma de cosmologia e contribui com o entendimento de mundo matemáticomecânico (MOREIRA, 2007). No intervalo de tempo entre o Renascimento e o Iluminismo, a cartografia de precisão alcançou seu auge (pela primeira vez). A Europa racionalista era o destino civilizatório de todos os povos, assim, o geógrafo organiza o mundo segundo a razão européia, produzindo mapas precisos com a finalidade de orientar os conquistadores do mundo, os naturalistas e os navegadores (MOREIRA, 2007).

Segundo Moreira (2007) o século XVIII (Iluminismo) consolida o geógrafo, o qual mapeia o mundo com rigor matemático, localizando os recursos que movem a nova economia (Revolução Industrial e ascensão da burguesia). No século XIX e primeiras décadas do século XX surge a necessidade de melhor conhecer os povos e a relação homem/meio. Nessa época (começo do século XIX) diferentes profissionais tentam formular teorias de localização para racionalizar a organização do espaço com o fim de atender às necessidades de expansão da indústria. No século XX a Geografia é a ciência do espaço e o geógrafo é especialista de sua organização.

[...] o planejamento estatal vai conferir à geografia e ao geógrafo um dos momentos de ápice de sua historia. E será o responsável pela imagem pública de saber colado às representações de mundo - a "geografia do professor", de Lacoste - e às praticas de administração do Estado, dos governos e dos negócios - a "geografia dos estados maiores" -, em suas necessidades de intervenção territorial. E essa ligação contemporânea como o Estado se torna tão forte que o destino deste se torna o seu próprio destino (MOREIRA, 2007, p. 15-16).
Com o planejamento estatal há o resgate e atualização das antigas teorias de localização, porém em nível de grandes escalas. "Nasce, assim, o perfil do geógrafo ainda hoje existente, identificado com a tarefa da demarcação dos espaços diferenciados a partir da arma teórica e cartográfica da teoria da região, substituída hoje pela teoria do espaço em rede" (MOREIRA, 2007, p. 16).

A Geografia é sistematizada na Alemanha pouco antes da unificação nacional (1870), por Humboldt e Ritter; ambos valorizam a relação homem/natureza (MORAES, 1999). Humboldt e Ritter buscam a visão holista que possuem da natureza em Schelling, que no início do século XIX apresenta a filosofia da natureza, uma tentativa de retorno do homem à natureza (MOREIRA, 2007). Segundo Moreira, essa tentativa de retorno do homem à natureza é barrada pelo nascimento das ciências humanas no começo do século XIX, na qual o homem se torna tema de investigação, seu corpo se institucionaliza como social de uma parte e como natural de outra.

Ratzel viveu o Estado Nacional Alemão (1871) e publicou suas obras no último quartel do século XIX, as quais são consideradas por L. Febvre um "manual do imperialismo" (MORAES, 1999). 0 objeto central dos estudos de Ratzel foi a influência das condições naturais na evolução das sociedades e percebeu a relação homem/meio mediada pela política. De acordo com Moraes, Ratzel manteve a visão naturalista, reduziu o homem a um animal sem diferenciar suas qualidades específicas.

Ratzel, segundo Moraes (1999), formulou as bases da Escola Ambientalista a partir da influência de Haeckel, seu professor e primeiro formulador da Ecologia. Moraes (1999) escreve, também, que nessa Escola mantém-se a concepção naturalista, mas a natureza não é vista como determinação ou causalidade mecanicista, e sim como suporte da vida humana. Apesar disso, Ratzel é lembrado pelo seu determinismo geográfico.

Segundo Moraes (1999), a Geografia desenvolvida na França nesse período histórico, também, foi um reflexo de geopolítica: a disputa imperialista entre França e Alemanha culminou, em 1870, na guerra franco-prussiana, cujo resultado foi a derrota da França, a qual perdeu territórios muito importantes de sua economia. Assim, a geografia francesa, escreve Moraes, foi um diálogo com Ratzel e o principal artífice foi Paul Vidal de La Blache.

Paul Vidal de La Blache introduz a idéia da "necessária neutralidade do discurso científico" (MORAES, 1999, p. 65) na Geografia na tentativa de combater o discurso de Ratzel, e, assim, dissimular 
o seu próprio discurso de legitimação francesa, o qual foi muito mais sutil e mediatizado. Aumentou a carga humana na Geografia, mas não rompeu com a visão naturalista de Ratzel. Definiu a relação homem/natureza (mediada pela técnica) como o objeto da geografia, na perspectiva da paisagem, sendo que as trocas mútuas com natureza é que criam a superfície terrestre - possibilismo (MORAES, 1999).

Com o legado do possibilismo a França tornou-se referência da Geografia. Do projeto da obra "Geografia Universal" de La Blache nasceu a região como escala de análise, unidade espacial dotada de individualidade de suas áreas limítrofes (MORAES, 1999). Na Geografia Regional a carga naturalista é mantida e limita-se a explicar somente aquilo que é visível.

Moreira (2007) escreve que o geógrafo de agora tem que representar e explicar o visível e o invisível. Visível é a imagem do arranjo espacial; invisível é o plano metafísico das estruturas das relações que se manifestam nos padrões visíveis.

No curso do tempo, foi a dialética desse trânsito entre esses níveis o problema teórico e técnico que desafiou o geógrafo e de novo o desafia agora. Explicar o oculto por meio do aparente, sem cair no simplismo da mais tradicional das metafísicas [...]. 0 desafio agora se apresenta num tempo em que o princípio da incerteza se torna a base do entendimento, seja da estrutura quântica da natureza, seja da estrutura fluida da organização espacial da sociedade, obrigando o geógrafo a ter de trazer para esse campo relacional da sociedade e da natureza (a antiga e clássica relação homem/meio da geografia) a tarefa de reinventar seus meios de representação e de entendimento (MOREIRA, 2007, p. 20).

Em tempos de análises regionais especializadas (Geografia Agrária, Geografia Urbana, Geografia das Indústrias, da População, Econômica) a Geografia da França apresenta um autor avançado em suas formulações: Max Sorre. Suas publicações datam de 1940 e o principal conceito que apresentou foi o de "habitat", que referencia uma porção do planeta vivenciada por uma comunidade que a organiza; é uma humanização do meio que expressa múltiplas relações entre o homem e o meio (MOREIRA, 2007). "A Geografia de Sorre pode ser entendida como um estudo da Ecologia do homem [...], ou Ecologia Humana" (MORAES, 1999, p. 80-81).
A proposta de método de estudo de Sorre partia da Cartografia, com a sobreposição de dados da observação, analisando historicamente a formação dos elementos naturais até os sociais; dito por Moraes (1999), primeiramente histórico e parcelado, e depois, ecológico e integrado. Eles são espaços sobrepostos em inter-relação, o que veio a ser a segunda grande formulação da Geografia francesa (a primeira foi La Blache com a Geografia Regional), no sentido de um conhecimento global e unitário (MORAES, 1999).

Apesar desse grande passo para o estudo integrado da relação homem/meio de Sorre, foi a região de La Blache que ganhou maior atenção e contribuição com estudos posteriores. Afinal, a Geografia Regional pretendia ser o resgate da tradição holista de Humboldt e Ritter, a esperança para unir Geografia Física e Humana (MOREIRA, 2007). O pensamento geográfico tradicional, segundo Moraes (1999), encerra com o dualismo da Geografia Física, Humana e Geral.

A Geografia Pragmática se caracterizou pelas novas técnicas, geotecnologias (Sensoriamento Remoto e Geoprocessamento), para fins de planejamento. Também se caracterizou pela passagem do positivismo para o neopositivismo, uso de modelos e teoria sistêmica (MORAES, 1999). A geografia ganhou maior dinamicidade, porém, Moreira (2007) relembra a critica mais contundente feita a essa Geografia: são novas idéias e novos instrumentos, mas ainda presos aos velhos conceitos.

Daí que o geógrafo caia freqüentemente
no fetiche do poder da técnica. No pas-
sado, achou que a fotointerpretação era
a interpretação da foto, quando era a
descrição do que estava fotografado. No
tempo da geografia quantitativa, achou
que a câmara bastava. E hoje acha que
basta o programa de geoprocessamen-
to. 0 problema é que nem a fotografia
aérea, nem os modelos quantitativos e
menos ainda o programa de geoproces-
samento pen sam e interpretam o
mundo por si mesmo (MOREIRA, 2007,
p.21).

Paralelo a isso há o empobrecimento da reflexão geográfica, o discurso fica mais pobre em essência, porém com linguagem mais rica e elaborada; há o fracionamento do objeto de estudo; e a especialização com a finalidade utili- 
tária, que leva à perda de qualquer perspectiva (MORAES, 1999). De acordo com Moreira (2007), na Geografia Neopositivista a morte da história acontece quando se reduz o espaço a um mero discurso de pontos e linhas; é a idéia do espaço feito somente de formas, sem conteúdo.

Não se pode deixar de mencionar que a região foi substituída pela rede; esse todo (a rede) onde a diferença (re)aparece, na forma do lugar trazendo o espaço de volta e recolocando os termos da representação geográfica - a rede encarna a presença da diferença (MOREIRA, 2007). Segundo Sposito (2004), os temas mais significativos desenvolvidos em Geografia Quantitativa foram os movimentos, as redes, os nós, as hierarquias e as superfícies. Trata-se do reflexo de uma nova perspectiva, usando, inclusive a linguagem da Teoria Geral dos Sistemas de Bertalanffy (1973).

Essa mudança de visão, de percepção, foi acompanhada pela ascensão do pensamento sistêmico. "No século XX, a perspectiva holística tornouse conhecida como 'sistêmica', e a maneira de pensar que ela implica passou a ser conhecida como 'pensamento sistêmico'" (CAPRA, 2006). "Ecológico" e "sistêmico", segundo Capra (2006) são termos que podem ser usados como sinônimos, sendo este, o termo científico mais técnico. Na ciência geográfica as características de um pensamento sistêmico emergiram no início do século XX. 0 entendimento sistêmico do ambiente envolvendo o homem, também, fora tratado com outras terminologias que não aquelas da Teoria Geral dos Sistemas, mas, que, no entanto, possuíam mesmo significado prático. Chorley, em 1962, segundo Chistofoletti (1999) foi o primeiro a introduzir na literatura geográfica (mais precisamente em Geomorfologia) o estudo de sistemas.

Nos anos 1960, os geógrafos humanos adotaram amplamente o uso da terminologia sistêmica, sendo de Haggett, em 1965, o texto pioneiro (JOHNSTON, 1986). Segundo Johnston (1986), a abordagem sistêmica foi firmemente adotada pelo estudo que cobre a área de contato entre a Geografia Humana e a Geografia Física.

Numa esfera mais humanística está a Geografia da Percepção ou Comportamental, a qual se ocupa de como os homens percebem o espaço vivenciado e como refletem na ação sobre o espaço. Nesta Geografia, tentam explicar a valorização subjetiva do território. Usa-se para tal o instrumental da psicologia behaviorista, a exemplo: o comportamento do homem urbano em relação aos espaços de lazer, a influência das formas, a relação da sociedade com a natureza expressas na organização dos parques (MORAES, 1999). 0 método fenomenoló- gico-hermenêutico é muito usado nos trabalhos de Geografia da Percepção. As atenções são voltadas àquilo que é percepção subjetiva do ambiente, o que não deixa de ser o discurso da relação homem/meio.

Com muitos argumentos a favor de uma sociedade mais justa e pensando a geografia como instrumento de libertação do homem, surge a proposta de uma Geografia militante-política, a Geografia Crítica (década de 1970). É a época da emergência do marxismo e da fenomenologia em Geografia, embora o marxismo não "vingue", devido, segundo Moreira (2007), à fenomenologia. E ademais, segundo ele, o marxismo separa ciências naturais das humanas e das humanidades.

Moreira (2007) escreve a respeito dos clássicos modos de ver e pensar: um histórico e outro que surge na década de 1970. 0 modo de ver e pensar clássico tem o seguinte ponto de partida: geografia é o estudo da relação homem/meio, e logo no começo é dicotomizado, ou seja, o homem é objeto da geografia humana e a natureza da geografia física. A noção de relação e organização, que não opera desde o inicio não permite desenvolver um raciocínio de relação ambiental e organização espacial.

A partir de 1970 tem-se o modo de pensar, de ver e de representar, de orientação marxista. A relação homem/meio possui caráter conflitivo e dicotômico devido à perspectiva que separa os homens em proprietários e não proprietários do objeto espacial e seus elementos; e isso, também separa os homens entre si (MOREIRA, 2007).

"O geógrafo operou e opera ainda agora, com um conceito externo e matemático de espaço, tempo, homem e natureza que são filhos diretos da física mecânica criada entre os séculos XIII e XVII" (MOREIRA, 2007, p. 120). E até hoje a relação homem/meio é vista embutida numa arquitetura de tempo-espaço matemático mecânico. Dever-seia resgatar a tradição da Geografia que relaciona homem/meio na arquitetura holista da espacialidade diferencial, cujo resultado é "[...] fazer do espaço um tecido formado pelo complexo de todas as relações que intervêm na transformação da superfície terrestre como verdadeiro espaço da sociedade humana" (MOREIRA, 2007, p. 129).

Em estudos geográficos parecemos vivenciar a metáfora bíblica da criação do mundo, o homem foi o ultimo ato, como diz Moreira (2007), fica por ultimo no contexto espacial. Com isso, vivese o mal estar geográfico determinado pelo

modo de ser-estar-espacial criado como cultura no Ocidente, onde o homem está, mas não é o espaço. [Esse] mal-estar é uma mistura de desenraiza- 
desenraizamento e manipulação do imaginário que se põe em evidencia na forma das guerras de destruição, violência generalizada e perda de referência humana (MOREIRA, 2007, p.133).

A relação homem/meio como objeto central de estudos geográficos experimentou todo o tipo de abordagem, algumas desconhecidas, esquecidas e outras reproduzidas à exaustão. Essa é a herança de como se faz Geografia. É essa herança que se reproduz no imaginário e nos trabalhos das universidades, local por excelência, de circulação, reprodução e assimilação dos valores que permeiam a sociedade. Moreira (2007) chama arranjo ideológico a esse local onde o conjunto de valores ideológicos ganha força e se torna concreto. E vai além, quando escreve que esse arranjo ideológico é capaz de regular o espaço.

\section{A repercussão do entendimento da socieda- de/natureza nos trabalhos acadêmicos}

No exame de 26 (do total de 99) trabalhos acadêmicos, dentre monografias e dissertações defendidas pelo PPGGeo/UFSM, a característica mais marcante é a reprodução da conhecida dicotomia da Geografia: homem/meio, sociedade/natureza. Ratificando a principal dicotomia herdada da Geografia.

Observou-se que persiste a preocupação com a integração da sociedade à natureza e a maioria dos trabalhos busca fundamentos na perspectiva sistêmica, transformando-os em seu método de pesquisa, porém, com base na análise dos seus resultados, pode-se afirmar que a grande maioria não faz, de fato, uma análise sob tal perspectiva, ficando, os mesmos, atrelados à perspectiva analítica, evidenciada pela clara separação entre os aspectos sociais e naturais.

Alguns conseguem abordar sistemicamente a relação sociedade/natureza, outros aumentam o distanciamento entre essas duas categorias. Aqueles que logram superar a dicotomia sociedade/natureza são aqueles que optaram em sua pesquisa inserir o uso de questionário ou entrevista sócio-ambiental ${ }^{3}$, ou mesmo uma entrevista informal com os moradores da área de estudo. Estes conseguem ir além da avaliação superficial do meio e da condição humana/social.

Outra característica importante nos trabalhos que conseguem superar a dicotomia é a coincidência de serem trabalhos que iniciam a pesquisa com a caracterização da dimensão humana, contrariando o tradicional receituário de estudos geográ- ficos, que começam com a caracterização física, natural do objeto de estudo, para depois passar à parte humana, como na metáfora bíblica da criação do mundo. Nessa perspectiva o pesquisador dedica maior atenção e tempo aos fatores humanos, observa as relações invisíveis e estrutura a dinâmica espacial a partir dessas relações, ou seja, entende a ação humana como fator de modificação do espaço, da paisagem.

Isso inclui outra observação, que diz respeito ao invisível, já citado por Moreira (2007). Nos trabalhos que superam antigas dicotomias, a presença do que constitui o invisível é significativa, pois ela preenche lacunas no entendimento dos processos espaciais estudados pelo pesquisador.

A preocupação com a integração sociedade/natureza também está presente nos trabalhos que não superam a dicotomia, e, sim, a reforçam. Seus pesquisadores também, em geral, declaram utilizar a metodologia sistêmica, ou no mínimo declaram que pretendem entender o ambiente como um todo integrado, mas não obtêm o resultado almejado, pois não aplicam o método.

Em alguns casos, não raros, o autor propõe o estudo de determinada área aclarando que a presença humana é fator importante para seu estudo, no entanto, quando parte para os resultados ignora a presença humana, ou, a reduz em números, área de ocupação, porcentagem, área colorida do mapa temático, como se tratasse de um objeto inanimado, estático.

Nesses casos constatou-se uma identificação com a geografia naturalista, quando reduz o homem à sua biologia, sem suspeitar que o espaço sempre foi uma rede de relações dinamizada pelo homem e pelas relações econômicas. Esta verificação deu-se com mais frequência nos trabalhos que usam a quantificação e a imagem como produto final. As geotecnologias são muito úteis, mas a imagem, que é o produto final destes trabalhos exerce uma força expressiva muito grande, deixando mudo o pesquisador. Parece que ao pesquisador, que se envolveu bastante com o seu trabalho, tudo está demonstrado no mapa síntese; mas essa impressão, se é real, é só dele. Estes suprimiram a escrita e a análise daquilo que não está visível, ou seja, suprimem a informação daquilo que a imagem pode transmitir (empobrecem o trabalho) e ainda não descrevem os processos invisíveis do espaço (economia, sociedade, conflitos, política). Em suma, há um esvaziamento de conteúdo analítico.

Observou-se também, a separação dos subitens do trabalho em parte física e humana. Porém, 
nem todos que separam esses itens fazem uma dissertação dicotômica. Quando o afastamento persiste, em geral inicia-se com essa separação de itens acima mencionada e a presença humana é negligenciada nos resultados do trabalho. 0 homem fica por último, como nos receituários tradicionais de pesquisa em Geografia.

Em alguns trabalhos o homem apareceu como agente do meio somente quando havia o estudo do uso da terra para a agricultura e para a urbanização, e ainda assim, é uma análise superficial da ação do homem. O homem, neste caso, está separado da natureza e representa uma ameaça a ela. 0 ambiente é tratado como frágil e indefeso.

Observaram-se algumas características importantes quanto aos estudos que envolvem o mapa de uso da terra, quanto à elaboração de zoneamento ambiental, quanto aos mapas de conflito de uso da terra e quanto aos estudos de bacias hidrográficas. Comparando os trabalhos que participaram da amostragem, podem-se perceber algumas particularidades em relação aos temas supracitados. Alguns poucos trabalhos demonstram o entendimento de que o mapa de uso do solo (ou uso da terra) por si só é um produto da relação homem/natu-reza, é a materialização da influência humana no meio, sua capacidade de transformação, suas técnicas de produção, seu modo de vida, a economia familiar, a economia do município, política econômica, forças endógenas e exógenas, problemas sócio-econômicos, a relação preservacionista ou predatória com o ambiente, a percepção ambiental, a culturalocal.

Esses poucos trabalhos conseguiram ir além das quantificações, do tamanho do lote, da percentagem usada para agricultura, vegetação nativa, campo. Em geral, os trabalhos mais abrangentes e também profundos em compreensão, e na análise dos resultados, foram aqueles que incluíram em sua pesquisa o questionário ou a entrevista com os moradores locais. Estes foram, coincidentemente, os trabalhos mais ricos em termos de compreensão do espaço e das relações que estão nele estabelecidas, enfim, são os trabalhos que cumprem, quando se comprometem, a proposta sistêmica. Dito de outra forma, as pesquisas que se mostraram coerentes na aplicação da perspectiva sistêmica são aquelas mesmas que realizaram levantamentos de informações econômicas, sociais e ambientais através do emprego de questionários e/ou entrevistas, o que não significa que a simples aplicação de tais expedientes seja condição direta da obtenção de êxito na intenção de aplicar a perspectiva sistêmica no seu fazer científico.

Quanto aos trabalhos que usam, ou elaboram mapas de zoneamento ambiental, alguns auto- res entenderam que este mapa é muito significativo quanto ao seu conteúdo e função. A função do zoneamento ambiental é normativa, serve ao planejamento de um município, ou até de uma região. Seu conteúdo é integrativo, é em função da relação sociedade/natureza, reflete o contexto atual de ocupação, degradação, conservação e a partir disso, normatiza o contexto futuro. Assim, entendem alguns autores, que o zoneamento ambiental é em si a relação sociedade/natureza, da mesma forma que o é o uso da terra. Sua diferença está na particularidade de o zoneamento ambiental ser um instrumento de planejamento centrado no ambiente, a partir do ambiente. E a semelhança entre o mapa do zoneamento ambiental e o mapa de uso da terra está nas relações causa-efeito (causa: presença humana, efeito: mudança na paisagem), ou seja, podem ser formados pelo mesmo conteúdo, desde que o zoneamento seja normativo e parta das necessidades do meio e não do homem (diferem quanto à finalidade).

Na busca pela superação da dicotomia sociedade/natureza devem-se seguir os exemplos positivos, ter por base os trabalhos que sobrepujam essa dualidade. Assim, cria-se o hábito de pensar sistemicamente e deixa-se de lado a tradição da separação e da fragmentação das Ciências.

Alguns autores, não fizeram essa relação, relegando o zoneamento ambiental à análise superficial e unicamente quantitativa de uma série de mapas temáticos obtidos através de imagens de satélite ou fotografias aéreas. Houve até mesmo quem o fizesse sem conhecimento, reconhecimento empírico da área de estudo, ou seja, sem realizar o trabalho de campo.

O mapa de conflito de uso da terra é outro exemplo de síntese da relação homem/meio. Assim como no zoneamento ambiental, neles o foco é a política ambiental. As leis que regulam o país, o fazem em nome de todos os cidadãos, é um pacto social para que todos possam (gerações contemporâneas e futuras) desfrutar do ambiente saudável. Visto de forma ampla o conflito de uso da terra é um conflito de direitos e deveres, do privado e do público. É na investigação empírica que alguns autores descreveram o conflito como fruto de uma política econômica que sacrifica o produtor rural, beneficia os atravessadores e comerciantes e, novamente, sacrifica o consumidor final. No afã de manter o padrão de vida ou simplesmente o sustento da família, os produtores rurais aumentam sua área de produção na propriedade e avançam sobre as áreas protegidas pela lei. Alguns desses autores dão a perspectiva de quem é vítima de uma política econômica nacional submetida a uma internacional. A área produtiva de uma propriedade depende 
de quantos dependem dela para sobreviver, e o número aumenta conforme estaciona a oferta de emprego e conforme aumenta o tempo de contribuição dos trabalhadores ativos para poderem se aposentar.

No estudo de bacias hidrográficas observaram-se as mesmas questões. Em si mesma, a bacia ou sub-bacia hidrográfica foi entendida por alguns autores, se tratar da canalização do ambiente terrestre e do aquático, ou ainda, da soma de ecossistemas aquático e terrestre. A sub-bacia é um simulacro das bacias hidrográficas, independente do tamanho que possuam. Dessa forma alguns autores souberam integrar seus sofridos dados, e dar às bacias hidrográficas sua real dimensão, ou uma aproximação bastante fiel desta. Noutros casos, alguns autores desperdiçaram seu tempo de coleta de dados, sua dedicação à pesquisa, oferecendo uma interpretação baseada unicamente nos dados quantitativos, ou, dados quantitativos do ambiente. Esqueceram de acrescentar a presença humana.

Uma vez que os trabalhos do PPGGeo/UFSM são uma amostra da Ciência geográfica no Brasil, as antigas dicotomias continuam vivas e reproduzindo-se no âmbito do universo pesquisado. Ainda assim, a relação sociedade/natureza, segregada, não é somente herança da Geografia, mas de uma cultura ocidental que carrega o mito da expulsão do homem do Paraíso, o qual está bem vivo dentro de sua psicologia individual e coletiva.

\section{Considerações finais}

Há outra maneira de abordar a dualidade sociedade/natureza sem ser esta que usualmente e superficialmente adotamos? Essa pergunta recorda uma frase de Joseph Campbell (2008), a qual afirma ser difícil ouvir slogans e velhas palavras que encerram um significado já arraigado na sociedade, de maneira diferente, de maneira que não evoque instantaneamente e inconscientemente esses significados que já lhes foram atribuídos. Ou seja, é muito difícil romper com os mitos primordiais e modernos, com o mito do Paraíso perdido e a sua conseqüente separação homem/natureza, espírito/matéria, e da mesma forma, é muito difícil romper com a tradição da Ciência formal ocidental.

Feyerabend (2007) adverte que a ciência é somente um dos muitos instrumentos que as pessoas inventaram para lidar com seu ambiente. Tal alerta gera uma expectativa de superação da dualidade projetada para fora da Ciência que hoje vigora, que hoje detém o poder. Trata-se de impulsionar o pesquisador para além dos limites impostos pela Ciência, e pela sua maior realização, o método científico. É um convite para a superação do método.
Na busca pela superação da dicotomia sociedade/natureza devem-se seguir os exemplos positivos, ter por base os trabalhos que sobrepujam essa dualidade. Assim, cria-se o hábito de pensar sistemicamente e deixa-se de lado a tradição da separação e da fragmentação das Ciências.

\section{Referências}

BERTAlanfFy, L. von. Teoria Geral dos Sistemas. Tradução de Francisco M. Guimarães. Petrópolis: Vozes, 1973.

CAMPBELL, J. 0 poder do mito. Tradução: Carlos Felipe Moisés. 26.ed.São Paulo: Palas Athena. 2008, 242 p.

CAPRA, F. A teia da vida: uma nova compreensão científica dos sistemas vivos. Tradução: Newton Roberval Eichemberg. São Paulo: Cultrix, 2006, p. 256 p.

CHRISTOFOlEtTI, A. Modelagem de sistemas ambientais. São Paulo: Edgard Blücher, 1999. 236p.

DIEGUES, A. C. 0 mito moderno da natureza intocada. São Paulo: Hucitec, 1996, 159 p.

DOWIE, M. Refugiados da conservação. In: DIEGUES, A. C. (org.) A ecologia política das grandes ONGs transnacionais conservacionistas. Tradução: Antonio Carlos Diegues. São Paulo: Nupaub/USP, 2008, p. 113124.

FEYERABEND, P. Contra o método. Tradução: Cezar Augusto Morari. São Paulo: Editora UNESP, 2007, 374 p.

GONÇALVES, C. W. P. Os (des)caminhos do meio ambiente. São Paulo: Contexto, 1989, 147 p.

HUBER, R. Ambiência e mitos nos discursos e práticas acadêmicas: uma análise das monografias e dissertações do PPGGeo/UFSM. 2010. $157 \mathrm{f}$. Dissertação. (Mestrado em Geografia) - Universidade Federal de Santa Maria, Santa Maria, 2010.

JOHNSTON, R. J. Geografia e Geógrafos. Tradução: Oswaldo Bueno Amorim Filho. São Paulo: DIFEL, 1986, p. $155-172$.

MORAES, A. C. R. Geografia: Pequena história crítica. São Paulo: Hucitec, 1999, 138p.

MOREIRA, R. Pensar e Ser em geografia. São Paulo: Contexto, 2007, $189 \mathrm{p}$.

SPOSITO, E. S. Geografia e Filosofia: contribuição para o ensino de pensamento geográfico. São Paulo: Editora UNESP, 2004, 218p.

SUERTEGARAY, D. M. A. 0 atual e as tendências do ensino e da pesquisa em Geografia no Brasil. Revista do Departamento de Geografia (USP), São Paulo, n.16, 2005, p. 38 - 45. Disponível em: <http://www.geografia. fflch.usp.br/publicacoes/rdg/index.htm>. Acesso em: 8.02.2010. 


\title{
Society and nature in the academics works of (post)graduate education in geogra- phy and the geosciences/UFSM
}

\begin{abstract}
The relationship between society and nature is marked by the separation of the natural sciences and humanities, heritage and culture of occidental science. Is attributed to the distance between the Society and Nature, the myth of the expulsion from Paradise ,the separation in the pre-Socratic philosophy of spirit/matter and a series of events in the history of the Occident. This legacy was left to all sciences, including Geography, which becomes in its evolution, science contact society/nature. This research aimed to reveal how the familiar dichotomy between society/nature is discussed in the work of Postgraduate in Geography and Geosciences/UFSM. We examined 26 studies Postgraduate (between monographs and dissertations) which focus on environmental analysis. Of these, there were the content and the discourse advocated in the theoretical/methodological comparing them with the analysis of results by the authors. It was verified that the decoupling society and nature, persists in the interpretation of most authors. In general, the theoretical foundation seeks to apply a systemic view of the object of study, however, these authors demonstrated in the analysis of their results to the understanding of the subject matter is fragmented, especially in relation to society and nature. There was less frequent studies that discuss society/nature without dichotomize them.
\end{abstract}

Keywords: Society/Nature. Evolution Of Geographical Science. (Post)Graduate. Scientific Methodology. Myths In Geography

\section{La sociedad y la naturaleza en los trabajos de postgrado académico de geografía e geociencias/UFSM.}

Resumen - La relación entre la sociedad/naturaleza se caracteriza por la separación de las ciencias naturales y de las humanidades; herencia de la cultura y la ciencia occidental. Se atribuye a la distancia sociedad/naturaleza, el mito de la expulsión del Paraíso, la separación de la filosofia presocrática de espíritu/matéria y más de uma serie de eventos en la historia de Occidente. Este legado fue dejado a todas las ciencias, incluyendo la geografía, que se convierte, em su evolución, en la Ciencia de contacto Sociedad/Naturaleza. Esta investigación tuvo como objetivo revelar cómo la dicotomía de la Sociedad/Naturaleza se discute en el trabajo de estudios de Posgrado en Geografía y Geociências/UFSM. Se examinaron 26 estudios de Posgrado (entre monografías y tesis) que tienen que ver con el análisis del medio ambiente .De éstos, observado contenido y discurso defendido en los fundamentos teórico/metodológicos en comparación con el análisis de los resultados de los autores.Se encontró que el desacoplamiento sociedad/naturaleza, persiste en la interpretación de la mayoría de los autores. En general, el método teórico trata de aplicar una visión sistémica del objeto de estudio, sin embargo, estos autores demostraron en el análisis de los resultados que la comprensión de lo objeto de estudio es fragmentado, especialmente en relación con la sociedad y la naturaleza. Hubo menos frecuentes los estudios que tratan sobre la sociedad/naturaleza, sin dicotomizar ellos. Coincidentemente, comienzan su investigación por los aspectos que caracterizan a los procesos sociales.

Palabras clave: Sociedad/Naturaleza. La Evolución De La Ciencia Geográfica. Posgrado. Metodologia Científica. Mitos En Geografía. 